\title{
IBN 'ARABĪ/LLANSOL: EL VIAJE A TRAVÉS DE UNA RAZÓN ASOMBRADA
}

Julia Alonso (Universidad Nacional de Educación a Distancia)

Recibido el 19/9/2018. Aceptado el 15/4/2019.

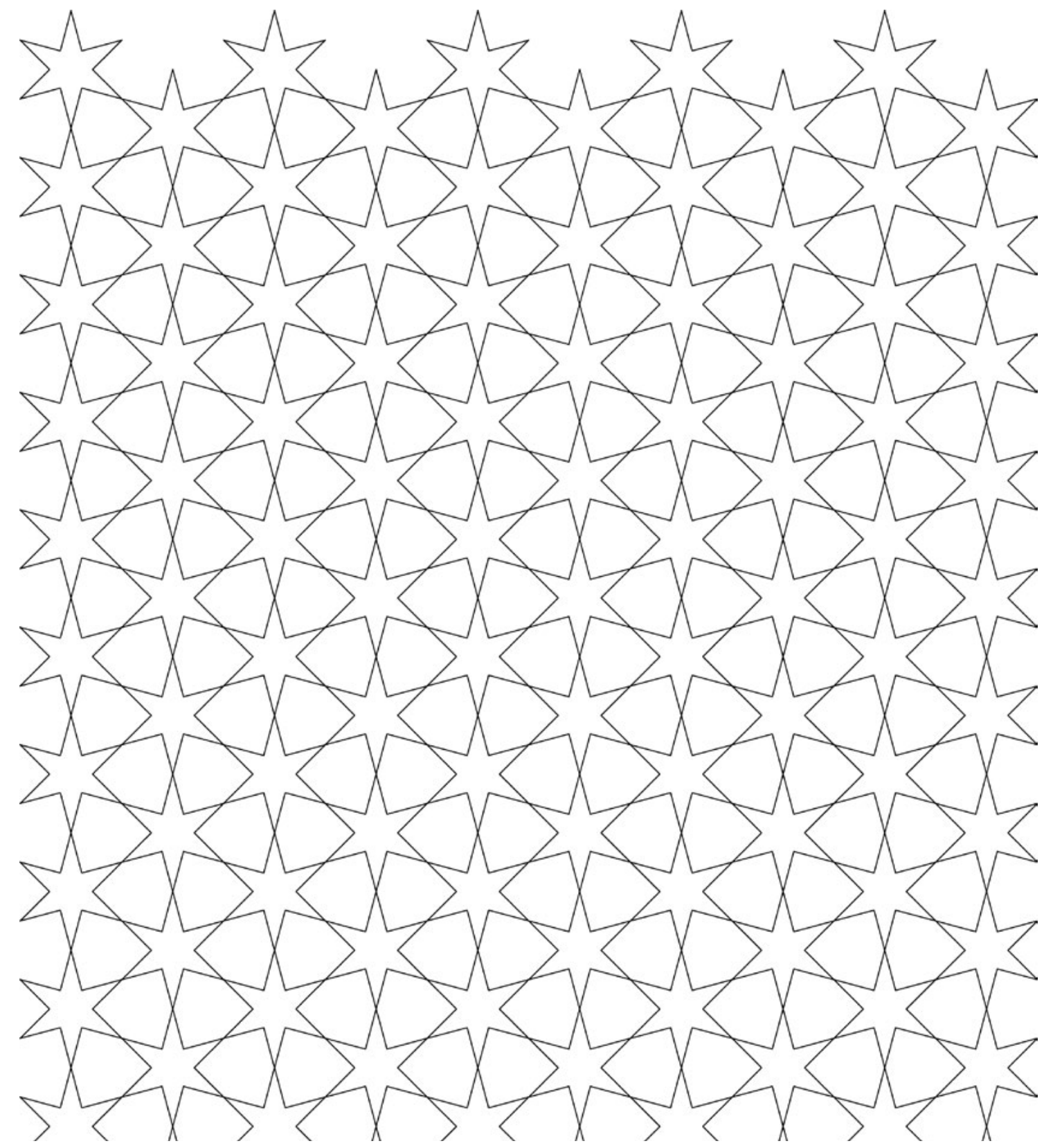


Resumen: Esta es una reflexión sobre el viaje espiritual emprendido por Ibn 'Arabī y Maria Gabriela Llansol, dejando patente que la distancia histórica no es óbice para que esta odisea del espíritu se perpetúe en el ser humano impulsado por el anhelo, que conduce a un conocimiento noético capaz de sortear el espacio-tiempo ordinarios y hacernos disfrutar con la «fiesta gadameriana» del instante. Esta atracción inexplicable se halla mediada por la Saudade, la Señora de la Noche pessoana, la diosa de Pascoaes y también de Parménides, la que de su mano conduce a los iniciados al ámbito, el entre-ser, en el que se advierte la presencia de un mundo imaginal al que lleva un sendero poblado de cromatismos que representan otros tantos estados del alma. El juego de los colores en el sufismo y en la obra de Llansol, da lugar a visiones deslumbrantes y paradójicas, poniendo de relieve la existencia de un universo extravagante, tan solo al alcance de los soñadores bienaventurados.

Palabras clave: Viaje espiritual. Anhelo. Mundo imaginal. Entre-ser. Colores.

Abstract: This is a reflection on the spiritual journey undertaken by Ibn 'Arabī and Maria Gabriela Llansol, making it clear that historical distance is not an obstacle for this odyssey of the spirit to be perpetuated in the human being driven by longing, which leads to a noetic knowledge capable to avoid the ordinary space-time and make us enjoy the «Gadamerian party» of the moment. This inexplicable attraction is mediated by the Saudade, the lady of Pessoa's night, the goddess of Pascoaes and also of Parmenides, who by her hand leads the initiates to the realm, the between-being [entre-ser], in which the presence is noticed of an imaginary world to be reached through a path full of chromatisms, that represent so many other states of the soul. The game of colors in Sufism and in the work of Llansol, gives rise to dazzling and paradoxical visions, highlighting the existence of an extravagant universe, only within reach of the blessed dreamers.

Keywords: Spiritual journey. Desire. Imaginal world. Between-being. Colors. 
Hay tres cosas que dan miedo: la primera, la segunda y la tercera. La primera se llama vacío provocado, a la segunda se le dice vacío continuado, y la tercera es también llamada el vacío vislumbrado.

Maria Gabriela Llansol ${ }^{1}$

\section{VIAJE AL ESPAGIO VERDE}

Encontrei este país no caminho da minha deambulação. Não havia outro que, como este estivesse, apesar de imóvel, tão preparado para ser outro. Abri-lhe uma esperança na cor verde da última janela na janela dos apaixonados do Poente e das Quedas de altivez.

Maria Gabriela Llansol ${ }^{2}$

La obra de Maria Gabriela Llansol nos remite a la pretérita idea del «viaje» visionario, aquel que conduce al humano exiliado de sí desde la ignorancia a la sabiduría, es decir, a la luz, a un mundo pleno de color, avistado desde una vertiente femenina y, por ello, capaz de recuperar un conocimiento iluminado por la Sophia.

Este trayecto más que un camino definido, lógico y fácilmente transitable es un vericueto, así lo ponen de manifiesto el ilustre sufí murciano Ibn 'Arabī (al-šayh al-akbar, 1165-1240) y Llansol (19312008) en sus textos. En consecuencia, tal como sucede con el pensador andalusí, la obra de Llansol no se puede sistematizar ni acotar mediante categorías filosóficas, ya que se asoma a una dimensión liminar en la que se produce la apertura espiritual hacia la Unidad del Ser que subyace a la aparente multiplicidad. Ibn 'Arabī y Llansol en su viaje hasta lo desconocido diseñan, cada uno a su manera, una muy peculiar cartografía espiritual caracterizada por el pasaje a través de profundos estados de conciencia visionarios y místicos en los que se pone de relieve la fuerza simbólica de las tonalidades ligadas a un universo femenino ${ }^{3}$.

Este es un tránsito amoroso, no exento de dolor, en tanto el auténtico amante se debate en el desasosiego que le incita al nunca satisfecho conocimiento que se da en la unión, el encuentro con el Amado. La instancia de la Saudade se hace manifiesta en los dos autores, en tanto se presenta como fuerza atractiva y elemento mediador entre lo Absoluto y el mundo frágil de los entes, al propiciar

1 Maria Gabriela Llansol, El Libro de las Comunidades, Madrid, Visiónnet, 2005, p. 9.

2 Id., Lisboaleipzig: o encontro inesperado do diverso. O ensaio de música, Porto, Assírio \& Alvim, 2014, p. 369.

3 Cf. Ibn 'Arabī, El Intérprete de los Deseos, Murcia, Editora Regional, 2002. 
la irrupción de lo eterno en el plano temporal, configurándose como la Diosa-Madre que da a luz un Nuevo Dios Infante. Y es esa potencia la que abre brechas en los relatos del poder, al reivindicar la libertad humana, haciéndose eco, en el caso de Llansol, de la fuerza que nos legaron seres gravemente heridos al tratar de redimir lo que está atrapado. Esta posición nos permite leer en otra clave la cultura europea, con plena conciencia de lo que no fue, pero debiera haber sido. No menos resistencia a lo establecido ofrece Ibn 'Arabī, quien se enfrenta en su tiempo a la ortodoxia dominante al plasmar otra búsqueda de la verdad, en la que cada ser humano se hace responsable de su pasaje interior hacia otro saber.

En definitiva, el encuentro con estos dos poetas nos introduce en profundidades incognoscibles fruto de estados místicos que terminan por anular el yo personal, para terminar por adentrarse en «otro Yo» Universal, en una corriente continua que supera a todo ente englobándolo en la Unidad metafisica de pertenencia. Es un fascinante viaje espiritual que al transitar por planos de realidad inconmensurables, permite la manifestación de lo divino en las teofanías coloristas ligadas, en el caso de Llansol, a los mundos animal, vegetal y mineral generando una profunda intercomunicación entre todos seres, a la vez que propone soluciones para «una mejor vida» en la que el Amor, como en el caso del escritor murciano, llega a tener un protagonismo determinante.

De alguna manera la totalidad de la producción llansoliana describe el itinerarium in deum, el viaje sin fin (Ibn 'Arabī) hacia la patria interior y también anterior, aunque el Dios al que se refiere la autora sea una deidad muy particular, no humanizada, un Nuevo Dios «inimaginable, fuera del contexto religioso, incluso sagrado, ajeno a toda idea predeterminada y tan evidente que por norma pasa desapercibido» ${ }^{4}$.

Podríamos afirmar con Henry Corbin que nos hallamos frente a «una teología de la soledad que nace de la noche oscura y del sufrimiento del alma ${ }^{5}$. En definitiva, es esta una religiosidad individual dispuesta en etapas características de un itinerario espiritual al que se accede por un impulso, por una pasión que hace "profesión de fe monadológica» y se desarrolla en el «microcosmos personal», conformando en este «desplazamiento inmóvil» todo un universo de figuras-acaecimientos psíquicos que se revelan al mundo de la experiencia interior, reconocidos como «Acontecimientos» e «interpretaciones de algo que trasciende». Escribe perpleja la Llansol: «¿Es esto un enigma? ¿Qué quiere decir esto? ¿Es un sueño despierto que se produce en la vigilia, en el estado expectante de viaje?» ${ }^{6}$.

Encuentros igualmente sorprendentes se dan en el camino (tarīqa) transitado por Ibn 'Arabī. En su obra El Esplendor de los efectos del Viaje, aborda el maestro sufi los frutos místicos y ontológicos de esa experiencia peregrina que se proyecta de alguna manera sobre todo lo existente, proveyendo otra

4 Cf. M. G. Llansol, Lisboaleipzig, cit., p. 145-46. Traducción nuestra.

5 Henry Corbin, Acerca de Fung, el Buddhismo y la Sophia, Madrid, Siruela, 2015, pp. 101-102.

6 M. G. Llansol, Um Arco Singular, Livro de Horas II, Lisboa, Assírio \& Alvim, 2010, p. 32. Traducción nuestra. 
percepción de la realidad. La deambulación descrita en estos textos es un canto poético a la nostalgia infinita, a la Saudade, la Señora invocada por Pascoaes y Pessoa, al amor transformador y alquímico que lleva implícita el ansia de resurrección fruto de una libertad espiritual absoluta, gracias a la cual se manifiesta la potencia de la imaginación creadora, otro territorio inexplorado que se ofrece a un conocimiento distinto del racional, poniendo de manifiesto el poder del espíritu que, en este caso, se objetiva en la obra de arte.

Fue Dufrenne ${ }^{7}$, precisamente, quien propuso una filosofía de los «a priori de la imaginación» y es, en este sentido, como se puede considerar esta función una fuente de objetividad, tal como lo entendía el poeta murciano y también Llansol. Bachelard ${ }^{8}$ estima que ese acontecer se da en un tiempo pleno de ausencia en el que se abandona el curso ordinario de las cosas, porque imaginar, para el filósofo francés, es mudar, lanzarse a una muerte de sí que es vida nueva. Por otra parte, el lenguaje poético es la resultante de una experiencia excepcional manifestada y objetivada a través de la palabra alusiva y evocadora, mediante la cual se pone de manifiesto la voluntad expresiva del Logos en el que, realmente, somos y estamos.

Precisamente, en el caso de Llansol nos hallamos ante la puesta en acción de una facultad de la naturaleza humana, cuyo rasgo principal es el «acaecimiento» y no es este un poder menor, secundario ni subsidiario sino que crea mundos extravagantes tan reales como este que nos des-vive: la imaginación hace conocer el mundus imaginalis «de figuras imaginarias tentaculares, labirintos povoados de monstros, estrelas que obcecam. Este mundo apresenta-se, ao mesmo tempo, como imaginário e real, como espiritual e material» ${ }^{9} ;$ «Manifestação do "entresser"...»"

En ese lugar, en el denominado entreser, un mundo intermedio entre lo sensible y lo inteligible ${ }^{11}$, las escenas eclosionan de forma instantánea, para pasmo de esta viandante audaz que transita al modo de una peregrina fragmentada hacia lo desconocido, a través de estaciones (maqāmat) asociadas a teofanías coloristas, buscando en esas topografias visionarias fronterizas (barzah) el camino que conduce a la fuente de irradiación pre-eterna, otro mundo en un más allá que de forma irremediable nos remite a la tierra de hürqalyā, al octavo clima sufi, agazapada en lo profundo de la psique humana y que, una vez alcanzada, consiente otro tipo de visión, una panorámica amplia similar a la que divisa el halcón llansoliano, «o falcão», apostado en esta ocasión en el «puño» de la autora. Este es el mundo que se revela a los soñadores, a los elegidos capaces de visualizar otros territorios que aun estando

7 Cf. Mikel Dufrenne, Fenomenología de la Experiencia Estética, Valencia, Fernando Torres, 1982; id., La Noción de "A Priori", Salamanca, Sígueme, 2010.

8 Gaston Bachelard. L'Air et les songes: essais sur l'imagination du mouvement, Paris, José Corti, 1981, pp. 9-10. Cf. Id., Fragmentos de una Poética del Fuego, Barcelona, Paidós, 1992.

9 M. G. Llansol, Um Arco Singular, cit., p. 182.

10 Ibid., p. 185.

11 H. Corbin, Templo y Contemplación, Madrid, Trotta., 2003, p. 184. 
ahí resultan invisibles para la mayoría, condenada a la simple percepción, a un des-vivirse. Y porque en determinadas circunstancias «lo absurdo tiene su ley», sobre todo en el mundo onírico, Pessoa en el Libro del Desasosiego, hace referencia en diversas ocasiones al estado de ensoñación, capaz de crear mundos paralelos a los de vigilia.

Sobre la potencia del sueño y de lo imaginal, escribe Bachelard:

Pero el sueño no sigue la razón. Cuanto más fuerte es la razón que se opone a un sueño, más profundiza éste sus imágenes. Cuando el ensueño se entrega realmente, con todo su poder, a una imagen adorada, es dicha imagen la que lo ordena todo. Entonces lo absurdo tiene una ley. Mientras se juzga el sueño por lo exterior, sólo se le reconoce una absurdidad descosida, fácil de imitar en obras que son únicamente parodias de la vida onírica. Se explica entonces el sueño por la pesadilla, sin ver que la pesadilla es la enfermedad del sueño, la ruptura y la desorganización de las fuerzas oníricas, la mezcla informe de las materias oníricas elementales. Pero el sueño y el ensueño dan, al contrario, a nuestro ser, una bienaventurada unidad. ${ }^{12}$

Tanto en el caso de la escritora portuguesa como en el del poeta andalusí, asistimos a la entrada en el mundo del alma (malak $\overline{\mathbf{u}} t)$ y en el de las formas imaginales ('âlam al-mitâ̄ $l)^{13}$. Tal viaje no deja de ser, por otra parte, un combate espiritual en el que se lucha por alcanzar la gnosis, el conocimiento supremo, que deriva en iluminación interior contemplativa $(\text { mušā } h a d a)^{14}$.

$\mathrm{El}$ anhelo, motor del viaje «o éxodo é um desejo» ${ }^{15}$, impulsa a la consecución de la restitución en lo propio, a una renovación, a un morir antes de morir, a un ascenso, a la aniquilación del yo (anā) y a una resurrección que permite al peregrino ser habitante de un plano originario, el de la tierra de las visiones de los cuerpos espirituales, el inter-mundo, cuya atmósfera, a medida que se asciende en ella, resulta bañada por colores diversos entre los que destaca el «color verde» («Desejava dirigir-me para o verde como uma perfeição impenetrável» ${ }^{16}$ ) que en el sufismo supone primor y culminación de la elevación espiritual. El verde, predominante en los textos de Llansol, aparece reflejado en las florestas, jardines, plantas y paisajes detallados en sus escritos. Esta tonalidad nos remite a la Visio Smaragdina, al matiz de la Tábula Preservada donde todo está escrito antes del tiempo, a la coloración del alma universal y al matiz de los jardines del paraíso, también a la visión lumínica verdeante de Mircea Elia-

12 G. Bachelard, El aire y los sueños, México, FDCE, 1972, pp. 275-276.

13 Cf. H. Corbin, L'Imagination Créatrice dans le sufisme d'Ibn' Arabî, Paris, Flammarion, 1958, p. 29.

14 Ibn 'Arabī, El Libro de la Extinción en la Contemplación, Málaga, Sirio, 2007, p.29.

15 M. G. Llansol, Um Arco Singular, cit., p. 25.

16 Ibid., p. 50. 
$\mathrm{de}^{17}$, el «verde dorado» vinculado a un «espacio sagrado», al «lugar prohibido y paradisíaco», a un cierto plano distintivo, esférico, ligado a la vivencia plena en el «interior de una gran fruta» traslúcida en un instante en el que se hace manifiesta esa transparencia glauca como si de un "grano de uva» envolvente se tratara. En definitiva, este tránsito nos remite a la tonalidad esmeralda de los sueños visionarios de Ibn 'Arabī y a su metáfora del «Mar Verde», mediante la cual anuncia precisamente el color de lo divino, el conocimiento absoluto, la omnisciencia y el resplandor de la vida eterna ${ }^{18}$. También el verde, en la mística sufí es el color representativo de la perfección y la resurrección, simboliza «el precioso jardín esmeralda» (Nizāmī) «el verdadero vergel» al que se refiere Rūmē, en el jardín de la visión reseñado por Hāfiz ${ }^{19}$.

Así pues, el verde es el color mediante el cual, en los textos y tratados sobre fotismo y metafísica de la ${ }_{l u z}{ }^{20}$, se determina una estación mística superior, fruto del viaje visionario que transcurre desde la ignorancia a la sabiduría y que, en el caso que nos ocupa, se pone de manifiesto en los jardines que circundan las diversas «Casas» habitadas por Llansol, entre las cuales emerge en otro plano de realidad, Lisboaleipzig, otra «Morada» intemporal, la de la familia de los Bach, en la cual habita un avatar, Infausta, junto a su reverso Aossê ${ }^{21}$, Pessoa mismo, el alter ego pessoano creado por la autora, quien «con las manos en los bolsillos mira hacia un prado verde» ${ }^{22}$. Esta Casa virtual, musical y poética, se halla dividida en dos partes una exterior ajardinada, verde, a la que se abren las ventanas y otra interior, donde se produce la visión que la propia «heterónima» Infausta tiene de Aossê ${ }^{23}$, es decir, de la otra parte de sí mismo del poeta, la hembra inconfesable que permaneció siempre encarcelada. La otra de sí oculta. «Infausta, la mujer vestida de verde, con el aspecto de mujer clorofila, a quien Aossê besaba los pigmentos $[\ldots] »^{24}$.

La incursión en el cosmos llansoliano no deja de ser una experiencia mística particular cuajada de símbolos, una marcha a través de ambientes insólitos en los que se dejan ver mundos volátiles, pobla-

17 Mircea Eliade, La Prueba del laberinto, Madrid, Cristiandad, 1980, pp. 20-21.

18 Cf. Antoni Gonzalo Carbó, «El viaje espiritual al espacio verde: El jardín de la visión en el sufismo», ponencia pronunciada en Homenaje a Henry Corbin, Universidad Complutense de Madrid, Casa de Velázquez, Instituto Francés de Madrid, 8 de abril de 2003.

19 Ibid.

20 Cf. H. Corbin, El Hombre de luz en el Sufismo Iranio, Madrid, Siruela, 2000, p. 11.

21 Aossê, es el nombre de Pessoa invertido, el envés del creador de los heterónimos, el auténtico Fernando Pessoa que nunca quiso reconocerse por haberse perdido en el laberinto de sus «otros». Llansol trae a la luz, la vertiente femenina del poeta, Infausta, personaje literario creado por la autora que interacciona con los habitantes de la Casa de Bach, ubicada en un plano intemporal musicado: Lisboaleipzig.

22 M. G. Llansol, Lisboaleipzig, cit.., p. 161.

23 Id., O Azul Imperfeito, Livro de Horas V, Lisboa, Assírio \& Alvim, p.109.

24 Ibid., p.135-36. Traducción nuestra. 
dos por efigies arquetípicas y primordiales propias de un universo imaginal en el que se multiplican acontecimientos asombrosos, ligados a una comunidad mistérica conformada por personajes-figuras vencidos, humildes, legendarios y fantásticos que emergen en «un istmo, que puede estar con nosotros, en el mar de al lado, o simplemente durmiendo» ${ }^{25}$. Con esos compañeros soñados traza el camino, amplía el plano de vivencia de una dispersa y oculta comunidad.

Estas figuras, definitivamente incluidas en el drama europeo ${ }^{26}$, nos dice la autora, no son sino personajes históricos o míticos; plantas o animales: «um dispositivo de companheiros que tomam parte na mesma problemática ${ }^{27}$ y ven el mundo en Sobreimpresión, de forma que los paisajes y los tiempos se superponen sin que el poder ni la ortodoxia puedan impedir semejante licencia creativa. Adentrarse en este universo donde conviven en un mismo plano dialógico Müntzer (Protopatro), la beguina Hadewijch y sus compañeras, Ana de Peñalosa (alter ego de Llansol), Hamann, Camões, Eckhart, Suso, San Juan de la Cruz, Copérnico, Spinoza, Bach, Nietzsche, Hölderlin, Pessoa, Kafka, el árbol Prunus Triloba, el perro Jade, el poeta-halcón (Pessoa), la planta Filomena do Nó, gatos, gallos, peces, caballos, etc.; supone transitar por una cartografía inusitada que se sustrae a todo discurso racional y, sobre todo, a la conciencia diurna. Los actores de este drama místico son rebeldes ${ }^{28}$, protagonistas inusitados, que se enfrentan tanto a los espacios convencionales como a los tiempos lineales e históricos tratando de ofrecer otra forma de vida, otra tierra nueva, otra espiritualidad y otra perspectiva sobre la naturaleza que nos rodea.

\section{UN INTERLUDIO: EL ENTRE-SER}

Llansol convoca a todas estas figuras en un contexto singular, el entre-ser, mediado por «el eterno retorno de lo mutuo» ${ }^{29}$ y es, a través de la escritura, como se requiere a esos otros para volver a recomenzar dentro de un plano «contemplativo de conversación amorosa ${ }^{30}$ ya que, dice la escritora, lo humano no puede definirse por el poder sino por «el encuentro con el amante, del cual el cuerpo es la manifestación presente y el texto la ausencia que se manifiesta» ${ }^{31}$.

En definitiva, es en su concepción de un mundo imaginal teñido de tonalidades $^{32}$ y gamas cromáticas

25 Ibid.

26 Id., Lisboaleipzig, cit., p. 139.

27 Ibid., p. 137.

28 Ibid., p. 138.

29 Ibid., p. 139.

30 Ibid.

31 Ibid.

32 Ibid., p. 143. 
ligadas a la potencia de Eros que así se manifiesta en cada «encuentro inesperado de lo diverso» ${ }^{33}$. De esta manera coincide la búsqueda de Llansol con la teoría del color y del amor de Ibn 'Arabī y los místicos sufís.

Por consiguiente, Maria Gabriela Llansol, a través de sus textos, conduce al legente hasta un espacio inaprensible, el de los ausentes, extraordinario, modelado por representaciones efímeras, transmutadas en «escenas fulgor» ${ }^{34}$ entintadas por el color de las atmósferas propicias. En este contexto surrealista la lectura forma parte de un proceso iniciático, una migración inédita hacia la tierra de hürqalyā, la más elevada del mundo imaginal donde lo imposible se hace posible, suscitando un itinerario que conduce hasta el país del no-donde, el Mundus Imaginalis descrito por Ibn 'Arabī, nivel de realidad que contiene las formas sutiles de todo cuanto principia y es manifiesto a los sentidos, topografía etérea en la que «lo espiritual se materializa y lo material se espiritualiza», tal como sostiene el al-šayh al-akbar, a donde conduce la Saudade, el ansia de regreso al origen, fuerza que confiere forma expresiva a las experiencias visionarias.

Este plano asombroso, esta topografía alucinada tan solo puede ser contemplada por los viajeros del espíritu. En él mora el duplo especular, sicígico ${ }^{35}$, de todo ente venido a la existencia. Y, sobre todo, resulta difuso su entendimiento para la razón porque siendo, a la vez, material e inmaterial se ubica en tras una línea verdeante que anticipa el resplandor de lo eterno. Esa ranura esmeralda, imprecisa, bordea y marca el tránsito entre realidades, es la línea verde a la que se refiere en un Dīwān el poeta persa Hāfiž, es la imagen que simboliza el mundo intermedio (barzah) descrito por Ibn 'Arabī, es umbral fronterizo y horizonte de sentido, es hendidura a través de la que se vislumbra una doble dimensión lumínica, otro grado de ser de las cosas, un territorio intersticial. Esta frontera ya fue advertida, en su momento, por Fernando Pessoa y también hoy inspira en gran medida las reflexiones del profesor Paulo Borges ${ }^{36}$. El barzah, es el espacio ístmico y metafísico, el Entre-Ser vislumbrado por Ibn 'Arabī, Pessoa y Llansol.

El Entre-ser pessoano se muestra como espacio de acaecimiento que se hace presencia en la plenitud de la ausencia, es apertura de lo inesperado, la eclosión del instante, Kairós, ligado al sueño. Llansol reconoce que esa topografia imaginal ya ha sido habitada por los místicos árabes. Ese interludio que se da entre la vigilia y el sueño, genera un espacio estético vinculado a la «imaginación creadora». A ese espacio determinado por la sobreimpresión se refiere la autora, el: «[...] entresser entre o sensível e o racional, a imaginação criadora da mística árabe, que é talvez de todas as manifestações de "sobrei-

33 Ibid.

34 Id., Da Sebe ao Ser, Lisboa, Rolim, 1988, p. 105.

35 H. Corbin, El Hombre de luz en el Sufismo Iranio, cit., p. 13.

36 Cf. Paulo Borges, «Vazio, Interlúdio e Entresser. A Metamorfose de Fernando Pessoa em Maria Gabriela Llansol», in Aa. Vv., Actas do Congresso Internacional Fernando Pessoa 2017, Lisboa, Casa Fernando Pessoa, pp. 320-330. 
mpressão", a mais portentosa» ${ }^{37}$.

Su descripción se da mediante una escritura-espejo, heterodoxa, que viene a convertirse y a representar, de alguna manera, el sostén material de un campo de fuerzas invisibles e imprevistas propiciando el advenimiento de los inexplicables fenómenos psico-fisicos ${ }^{38}$, los cuales se ponen de manifiesto mediante un verbo poético misterioso vinculado a una gama de colores que conforma espacios y niveles de realidad insospechados.

La fuerza de estos no-lugares radica en la emergencia de textos-figuras autónomas, heteronímicas, que advienen en un rapto, en un «centelleo», y adquieren vida a través de palabras fecundadas que ocultan en su seno el mensaje engendrado en otro nivel de realidad, desconocido incluso para quien lo escribe y describe. En este sentido, el poeta no es más que un medio a través del cual se pone de manifiesto la existencia de un plano simultáneamente sensible e inmaterial. Pareciera que un maestro espiritual invisible (Hidr) hablara al corazón (qalb). El propio Fernando Pessoa insinúa de forma críptica esta posibilidad aniquiladora de la conciencia personal cuando dice en uno de sus poemas: «No soy yo quien describe. Soy el lienzo. / Y, oculta, una mano colorea a alguien sobre mí. / Mi alma se perdió en lo que pienso / Y mi principio se extravió decidido en el Fin» ${ }^{39}$.

Y si la comunidad de figuras llansolianas, que se une en un solo cuerpo fulcral dividiéndose en rostros $\operatorname{diversos}^{40}$, es una colectividad dinámica y errante, la Comunidad pessoana resulta ser «una dispersión de semejantes que se transforman en el cerrojo de una puerta [...]. Está en el reino intersticial del solitario y del acompañado, en realidad esta es la tierra de nadie» ${ }^{41}$.

Pareciera que ciertas grafías guiadas, plenas de símbolos y alusiones suscitaran el avistamiento de lo que por su naturaleza es invisible al ojo humano, de manera que a través de ellas fuera factible el traslado del legente, el lector avisado, hasta el origen de un pensamiento que ha pervivido agazapado en misivas oraculares, en el poema de Parménides, en los fragmentos de Heráclito, en las teosofías de la luz, en las diversas gnosis y en las muchas manifestaciones vinculadas al conocimiento noético, cuyo legado fue reivindicado por María Zambrano ${ }^{42}$ en su formulación de la razón poética, donación concedida al ser humano y que sólo toma posesión de unos pocos, saber desinteresado, conocimiento herético que es purificación, o como sugiere Llansol, el medio por el que un día llegará a ser consumada la tan ansiada «libertad de conciencia» ${ }^{43}$.

37 M. G. Llansol, Lisboaleipzig, cit., p.139.

38 Ibid. p.52.

39 Fernando Pessoa, «Pasos de la Cruz», XI, in Id., Ficciones de Interludio, Buenos Aires, Emecé, 2004, p. 50.

40 M. G. Llansol, Lisboaleipzig, cit., p., 27.

41 Id., o Azul Imperfeito, cit., p. 110.

42 Cf. María Zambrano, Filosofia y Poesía, Madrid, Fondo de Cultura Económica, 2001, pp. $27-71$.

43 M. G. Llansol, Lisboaleipzig, cit., p. 140. 
En definitiva, en lo que se refiere a la obra llansoliana, nos hallamos frente a textos herméticos, escritos por una caminante de la Noche que ha sentido la presencia del Esse $e^{44}$, los cuales remiten de forma irremediable a una realidad no contada, aquella que nos traslada a lo que la autora denomina futuro anterior, incumplido y todavía vivo. La recuperación de lo olvidado y humillado trae a la actualidad otra comprensión de la vida y eso supone una sobreimpresión implantada en nuestra realidad cotidiana. Por consiguiente, nos hallamos ante la eclosión de un conocimiento marginal gracias al cual desde nuestro presente se impulsa la mirada hacia atrás, sin melancolía, vislumbrando otra Europa: Un nuevo Dios Infante, un nuevo Hombre, una nueva Ética, en definitiva, el regreso simbólico del simbólico «Rei D. Sebastián».

A medida que se profundiza en la obliteración del yo individual y emerge otro Yo-Universal que abraza la diferencia, los paisajes interiores adquieren tonos apropiados al instante puntual acaecido. A través de estas modalidades matizadas por diversas coloraciones lo inalcanzable e indecible, se revela de forma gradual. Es así como la autora va trasluciendo «climas» ligados al «climax» vivenciado, instantes fragmentados, materializados en ricas gamas de cromatismos oceánicos y húmedas atmósferas. Es ahí, en ese marco, donde seres vegetales entrañables (Filomena do Nó, Prunus Triloba...) rodean con afecto sereno y estático a los humanos agitados por estados de ser insólitos.

La intensidad con la que los actores de este drama viven su segunda oportunidad, y optan por otro camino en la encrucijada, se «aquieta» gracias a la presencia de animales que «saben» y «conocen» los enigmas de la existencia y el destino de todo lo mortal. Este discernimiento también se hace ostensible en el proemio alegórico del Poema de Parménides. Allí son yeguas, que «sabiendo», polýphrastoi, a donde van, tiran del carro y llevan, pherei, al «viajero» por el camino de la noche y del día, hasta la diosa que ha de recibirle:

Las yeguas que me llevan tan lejos cuanto mi ánimo podría alcanzar, / me iban conduciendo luego de haberme guiado y puesto sobre el camino abundante en palabras / de la divinidad, que por todas las ciudades, lleva al hombre vidente. / Por él era llevado. Por él, en efecto, me llevaban las muy atentas yeguas / tirando del carro $[\ldots] .{ }^{45}$

También el caballo Pegaso llansoliano es sabio porque piensa y «relincha palabras» ${ }^{46}$ a la diosa madre, al tiempo que se abandona al impulso anhelante, como hacen también los camellos presentes en las estrofas del Intérprete de los Deseos, de Ibn 'Arabī:

44 Ibid., p. 144.

45 Parménides, Poema, Barcelona, Orbis, 1983, p. 47.

46 M. G. Llansol, El Libro de las Comunidades, cit., p.41. 
Escribe Llansol:

El caballo, cuando cayó el rayo que incendió los pétalos, llamó a la dama la dama de las rosas, al perfume del desierto y a la comida que la mujer preparaba el todo y la nada [...]. La mujer comprendió que podía ver los pensamientos del caballo, otros pensamientos, y bajó los ojos hasta cerrarlos. ${ }^{47}$

Escribe Ibn ‘Arabī:

Los camellos aun con sus pezuñas / doloridas / en la noche sostienen su marcha / presurosa / Esas cabalgaduras nos trajeron hasta ti, / llenos de deseo, sin esperar por ello / recompensa. Hacia ti atravesaron lugares desolados y / arenales / con nuestra pasión sin quejarse por ello / de cansancio $[\ldots]{ }^{48}$

En este escenario profundamente espiritual, animista e inconcebible re-viven otras vidas quienes han sido silenciados. A ellos Llansol les regala otra oportunidad, la que permite re-formular y re-tomar propuestas y vivencias que en su momento fueron contravenidas o sofocadas. Así la autora recupera y reúne actores notables pertenecientes a épocas diversas, los cuales han destacado del común precisamente por su heterodoxia y marginalidad, o quizás lo que suceda es que trae al plano de la escritura sus dobles o sicigias.

En este mundo imaginal $l^{49}$ pleno de signos, pujanzas psíquicas y heterogéneas se producen transferencias inauditas. Así, quienes «ya han sido» cohabitan con los que «ahora son» y con los que jamás serán, en una realidad liminar heraclítea, fugaz, efervescente, cautiva de la incesante transformación una vez han sido rotas las barreras temporales y lingǘsticas. De esta manera, pasado, presente y futuro se funden en subterránea penetración habitada por instantes-fulgor efímeros, vivaces, grávidos y plásticos propios de un espacio fronterizo que, aunque parece no ser, ciertamente es.

47 Id., Geografia de Rebeldes, Madrid, Cinca, 2014, pp. 57-58.

48 Ibn 'Arabī, El Intérprete de los Deseos, cit., estr. XXVII.

49 Cf. H. Corbin, L'Imagination Créatrice dans le sufisme d'Ibn’ Arabî, cit., pp. 161-167. 


\section{LA OSGURIDAD: MATRIZ DE LA LUZ GOLOREADA.}

Al mirar el cristal, se vio reflejada en él. Por una ilusión óptica estaban los dos en el exterior de la casa; en el lado opuesto al río, donde hay una gran aglomeración de árboles multicolores y seculares.

Sobresalía el del centro, rojo - en medio de todos reposa el rojo, había después, sumergido en una filigrana de follaje verde un arbusto blanco; y más lejos, siempre entre el verde multitonal, arbustos rosas y amarillos [...] Es el tiempo de la oscuridad: / el sol se mantiene todo el día más allá del horizonte $[\ldots]$.

Maria Gabriela Llansol ${ }^{50}$

Tanto en los textos de Ibn 'Arabī como en los de Llansol, nuestro mundo cotidiano se representa como el reflejo especular de otra realidad o realidades en él ensimismadas y prestas al descubrimiento. La indecibilidad e invisibilidad de la última esencia de las cosas, identificada con el color negro, no implica su separación definitiva de las mismas, ya que su esplendor se hace manifiesto en las teofanías, en las sensaciones externas e internas moduladas por una intensa gama de fotismos silentes y audiciones coloreadas, en los avistamientos, en los viajes místicos y psicodélicos siempre matizados por tonos y modalidades oportunas. Lo cierto es que la apelación directa o indirecta al juego de los colores dentro del universo llansoliano es una constante, y son estas percepciones las que nos remiten al Hombre de $L u z^{51}$ iranio. «Eu sinto-me atravessada pelos seres, pela sua luz, como um vidro» ${ }^{52}$.

Con referencia a ciertas experiencias visuales ligadas al silencio introspectivo y referidas, en este caso concreto, a la comunidad de beguinas por ella redimida, dice Llansol: «Reparo que há um novo visível na manhã, na tarde, ao anoitecer: qualquer que seja a hora há sempre uma de nós que tem o silêncio dentro de si $[\ldots] \gg^{53}$.

Escribe, también, reflexionando sobre los últimos días en su casa de Jodoigne: «Me asalta la preocupación por los colores y no me resulta indiferente su sentido, porque las figuras y los animales son particularmente sensibles a los colores y a los ruidos» ${ }^{54}$. Como sucede con Goethe y V. Kandinsky el color aparece en los escritos llansolianos vinculado a una significación interiorizada plasmada en figuras textuales que brotan y convergen en determinadas fases espirituales. Nos atrevemos a sugerir que

50 M. G. Llansol, El Libro de las Comunidades, cit., p. 89.

51 Cf. H. Corbin, El Hombre de luz en el Sufismo Iranio, cit.

52 M. G. Llansol, Um Arco Singular, cit., p. 216.

53 Id., Lisboaleipzig, cit., p. 20.

54 Ibid. 
nos adentramos en una psicología cromática, en la cual los procesos de apercepción lumínicos están íntimamente ligados a estados fluctuantes, supeditados a otros tantos soplos pertenecientes a grados de ascensión específicos. Por lo tanto, el desplazamiento entre estados y estaciones va fijado a una serie de coloraciones que se erigen como resonancias de la agitación e «inestabilidad» del corazón (qalb). Nada se puede conocer sino por sí mismo y como dice Ibn 'Arabī, decididamente el color del amante es el color del amado, lo que da idea de la unidad entre el sujeto afectado y la pujanza que todo lo sostiene: «El Amado me hizo aparecer el resplandor de su unión que hizo brillar mi ser y mi esencia más íntima ${ }^{55}$ De esta manera, tal como mantiene Kandinsky ${ }^{56}$, el color se transforma en un sonido interior capaz de hacer vibrar el alma y, concretamente en este caso supone la presencia de un hilo conductor que enlaza el mundus imaginalis ${ }^{57}$ con la vida cotidiana, cuyo límite está en esa niebla móvil, la cortina de encajes entrevista por la autora, tras la cual se adivina otra realidad que nace de la plena oscuridad.

Este proceso de gradaciones se corresponde con una migración espiritual que tiene por objeto la búsqueda del conocimiento del fuego primordial adivinado, tal como nos enseñaron los grandes maestros sufís. El itinerario es fruto de una ciencia ancestral que tiene por objeto el cuidado de sí, una fuga en solitario al suelo, al origen, a la Matria, lo que presupone una muerte (éxtasis supremo) en vida. Este es un camino que transcurre por «espacios de significados coloreados» ${ }^{58}$, un viaje pleno de transiciones y esperas, cuyo inicio es descenso hacia lo profundo, azabache y lóbrego, hacia nuestra propia singularidad desnuda, sabiendo de antemano que en la oscuridad está la plenitud de la luz. Ese es el sendero transitado desde antiguo, aquel que lleva con fatigas de la noche a la luminiscencia, de la muerte a la vida.

[...] oscuridad interior por donde se penetra a través de la nieve en las cosas tanto sensibles como insensibles apoyándose solo en la subida y subiendo. Por eso aquí le llamo escala y secreto porque sus grados y artículos son secretos, ocultos a toda sensibilidad y entendimiento. ${ }^{59}$

La ruta espiritual, el camino, hacia el conocimiento supremo es una constante en cualquier iniciación. Estuvo presente en los misterios caldeos y eleusinos, en el pitagorismo, en el neoplatonismo, en el chamanismo y en el corpus-hermético renacentista. Este es un peregrinaje interior practicado también por los gnósticos y herméticos. La vivencia del viajero y los mensajes recibidos sólo pueden ser descritos mediante una cierta «escritura celestial», inspirada «en el blanco del libro y en el blanco

55 Ibn 'Arabī, Tratado del Amor, Madrid, EDAF, 2018, p. 31.

56 Vasili Kandinsky, De lo espiritual en el arte, Barcelona, Barral, 1981, p. 59.

57 M. G. Llansol, Lisboaleipzig, cit., p. 33.

$58 \mathrm{Ibid}$.

59 Id., El Libro de las Comunidades, cit., p. 55. 
libre» ${ }^{60}$. En este transcurso adquiere relevancia un campo sutil, caracterizado por la presencia de luces coloreadas que, en el caso de la teosofía de la luz irania preislámica y en los textos de Kubrā, Simn $\bar{a} \mathbf{n} \bar{\imath}$ y Sirhind $\bar{\imath}$, se corresponden con estaciones y estados del alma, fruto de la transformación espiritual. Es en este merodear donde las atmósferas coloreadas revelan la etapa del viajero, estableciendo correspondencias y encuentros entre mundos sensibles y suprasensibles.

El conocimiento generado en esta transformación lumínica se gesta en el Corazón, qalb, y concierne al secreto vinculado a la visión mística individual. Es pues este un saber derivado de una visión gnóstica ligada a cierto espacio sagrado en el que tienen lugar revelaciones fascinantes, y donde se dibuja una peculiar metafísica de los cuerpos etéreos. En definitiva, tanto los textos llansolianos como los de Ibn 'Arabī ponen de manifiesto la preeminencia de una psicofisiología propia de esa geografía intermedia. Ese plano en el que emergen las figuras textuales portadoras de fuerzas incógnitas: mujeres beguinas, rebeldes, místicos, gente anónima, poetas... es similar, escribe Llansol, a una morada que está de paso. Geográficamente, se puede estar de acuerdo con ella en que «es una encrucijada de lo espiritual, en un sitio aún vacío» en el que la autora se pregunta por sí misma y a sí misma: «O que passou aqui? O que é que aqui, no que se passou, continua a passar? ${ }^{61}$. Ese mapa se corresponde con el inmaterial y original pensamiento, la inexplicable intuición, la pujanza del sentimiento y la clarividencia de la imaginación, el Logos, denominada por Llansol cena fulgor, O Logos do lugar, «en que una morada de imágenes, doblando el espacio y reuniendo diversos tiempos, procura manifestarse ${ }^{62}$. Los habitantes que pueblan este «istmo», barzah, enlazan dos planos del ser, lo que permite afirmar encuentros y conexiones impensables.

En esta errancia a través de progresiones teñidas de luz se desarrolla la práctica que permite despertar la luminosidad íntima y propia, de forma que en ese movimiento se privilegian los instantes en los que cualquier topografía transitada irradia un fulgor oportuno, una brillantez irrepetible, gracias al cual el espacio adquiere las tonalidades pertinentes. La representación de paisajes teñidos de diversas gamas y tonalidades se corresponde con ese personal itinerario espiritual en el que emergen diversas $\mathrm{y}$ «absurdas» contemplaciones, propias de realidades metafísicas viajeras por el sendero que conduce hasta la puerta dominio del Uno/Todo, del Todo/Nada, de lo Universal.

Tan solo en un estado de rapto espiritual, ğ $a \underline{d} b a$, se puede mediante las luminiscencias alcanzar la aniquilación, fana $\bar{a}^{\prime}$, del yo empírico y cotidiano que impide el estado néptico, despierto, tal como mantiene Simnāñ̄. Esta es la muerte mística del yo, tópico frecuente en los caminos de transformación espiritual $^{63}$. Es así como se producen los fenómenos visionarios de las luces coloreadas que tiñen los

60 Ibid., p. 76

61 Id., Lisboaleipzig, cit., p. 135.

62 Ibid., p. 137.

63 Cf. Fernando Mora, Ibn al $\square$ Arabî, Vida y enseñanzas del Gran Místico Andalusí, Barcelona, Kairós, 2015, p. 232. 
objetos y los paisajes en la obra llansoliana cuyo origen se supedita a los centros etéreos reconocidos en el acervo iranio y sufi. Estas gradaciones de color se corresponden con estados de contemplación (murāqabah), con centros de conocimiento vinculados al alma sensitiva vital (azul oscuro), o azul imperfecto: «Pedra refazia os diferentes pontos do azul, e rendia sua imaginação a Ana de Peñalosa» ${ }^{64}$; al misterio (negro luminoso), «[...] es el tiempo de la oscuridad»"65; al secreto (blanco): «Vajra é a "cor branca" [...] como uma folha de papel branco muito lisa e opaca. Mas tem também o potencial de luminosidade, do brilho, do reflexo que é a sabedoria semelhante ao espelho» ${ }^{66}$; al corazón, qalb, (rojo rubí): «Ana de Peñalosa adoptó un pez de color rojo y rosa rojizo [...] al que dio el nombre de Suso» ${ }^{67}$ al cuerpo (gris oscuro), «o neutro»; al espíritu (amarillo) y a la verdad (el verde esmeralda brillante): «Torno-me prisionera da cor verde, é a mina luz de escrita: parece-me que regresso às fontes primordiais, quando se era água e diverso.» ${ }^{68}$.

Ese movimiento es dominado por un Deseo irrefrenable que incita al retorno, al origen mismo de la saudade, a lo propio, a la pre-eternidad, «al lecho materno» ${ }^{69}$ donde se oyen «cánticos sin que puedan afirmarse los pies en el suelo» ${ }^{70}$. El sujeto que enuncia, en su propia inseguridad, escribe Llansol, se dirige «ao ansiar do coração, e o coloca na sombra da dúvida. E se o coração persiste em ler, é porque há nele um fulgor estético que ilumina o próximo passo.» ${ }^{71}$.

El maestro Eckhart, figura recurrente en la obra llansoliana, también se refiere a esta atracción que conduce a la Unidad, la cual empuja al pobre de espiritu que nada quiere, nada sabe ni nada tiene hasta su preexistencia divina, cuyo rastro permanece velado en el corazón, y se manifiesta como deseo ligado a la espera de un cierto acontecimiento: la unidad con la causa inamovible que mueve todas las cosas.

[...] siento un impulso que me debe lanzar por encima de todos los ángeles. En dicho impulso siento una riqueza tan grande que Dios no me puede bastar con todo lo que Dios es, en cuanto Dios, con todas sus obras divinas, pues en ese atravesar me doy cuenta que yo y Dios somos uno. Entonces soy lo que fui y allí ni decrezco ni crezco, pues soy una causa inamovible, que mueve todas las cosas $[\ldots]^{72}$

64 M. G. Llansol, Um Arco Singular, cit., p. 45.

65 Id., El Libro de las Comunidades, cit., p. 89.

66 Id., Um Arco Singular, cit., p. 36.

67 Id., El Libro de las Comunidades, cit., p. 85.

$68 \mathrm{Ibid}$.

69 Id., O Azul Imperfeito, cit., p. 36.

70 Ibid.

71 Id., Lisboaleipzig, cit., p. 12.

72 Maestro Eckhart, «Sermón 52», in Id., Beati pauperes spiritu, México, Consejo nacional para la cultura y las 
Esa travesía se lleva a cabo por un camino sinuoso, hodós, rico en signos, polýphemon, que discurre entre arenas movedizas. La entrada a ese nuevo medio ${ }^{73}$ [...] tiene mucho que ver con estados alterados de conciencia, vinculados a fructíferas ensoñaciones.

El viaje iniciático, el camino ligado al delirio dionisíaco de quien ama la sabiduría, es afín a la vía de resurrección descrita en los textos órfico-pitagóricos, donde se hace referencia a una muerte que es vida ${ }^{74}$ y que conduce desde Parménides a Plotino, a los escritos herméticos y por caminos diversos recala en San Juan de la Cruz. El recorrido se halla pleno de dificultades porque no se ajusta al méthodos sancionado, en tanto sigue el camino de la sierpe $e^{75}$. Esas veredas conducen inexorablemente hasta un portón de «doble hoja» (Parménides) blindado, cuyo acceso resulta infranqueable para los que hasta allí viajan. Pocas veces llega a abrirse y lo hace sólo para algunos elegidos, los pobres de espiritu, los soñadores, aunque en realidad nunca termina de hacerlo, tan sólo deja sospechar la presencia-ausencia del otro lado, un universo ajeno al espacio-tiempo que configura nuestra realidad. Ese lugar, en el que como manifiesta el Maestro Eckhart: «los ángeles supremos, las moscas y las almas son iguales, allí, donde yo estaba y quise lo que fui y fui lo que quise» ${ }^{76}$, es la fuente ontológica de toda diferencia, ahí habita un algo que goza de sí mismo en la quietud y la oquedad, es esta una dimensión vacía de todas las cosas y en la que, sin embargo, todas las cosas son en su posibilidad y pre-existencia.

Lo cierto es que el hecho mismo de andar y des-andar presupone un juego de aproximaciones, en el cual el protagonista es un transeúnte que a medida que se despoja de su querer, de su tener y de su saber, deambula por un mapa errático, el sí mismo, cruzando y sorteando senderos que conducen a ese resquicio entrecerrado a través del cual se percibe el olor a hierbas (romero y menta) que alfombra la apertura ${ }^{77}$. A pesar de ello, no se distingue parte alguna ya que el camino conduce de forma inexorable hasta al Todo/Nada..., es decir, al oculto, negro secreto y umbroso abismo personal:

Entró en esa oscuridad interior por donde se penetra a través de la nieve en las cosas, tanto sensibles como insensibles, apoyándose sólo en la subida y subiendo. Por eso aquí le llamo escala y secreto porque sus grados y artículos son secretos, ocultos a toda sensibilidad y entendimiento. ${ }^{78}$

En este viaje se produce la mudanza de un plano de realidad a otro, donde diversos puntos de encuentro, convergencia de fuerzas y velocidades conforman una materia en la que predomina el color

artes, Dirección General de Publicaciones, 1998, p. 141.

73 M. G. Llansol, Lisboaleipzig, cit., p. 12.

74 Cf. Giorgio Colli, La Sabiduría Griega, Madrid, Trotta, 2008, pp. 145, 133.

75 Ibid.

76 M. Eckhart, «Sermón 52», cit.

77 M. G. Llansol, El Libro de las Comunidades, cit., p. 35.

78 Cf. Ibid., p. 55. 
blanco, al que Llansol le da el «nombre genérico de nieve» ${ }^{79}$. En ese espacio de entre-ser se produce el olvido de sí, necesario para avistar una «puerta», «o ponto voraz» ${ }^{80}$, tras la cual se abre un grande y profundo abismo «[...] as portas do ser; são portas deslumbrantes, além do que é humano, como o amor sobre o amon» ${ }^{81}$.

La deambulación llansoliana requiere la entrada y re-entrada a través de diversos cuartos que conforman la figura de una Casa cuyo amplio interior es también «blanco» ${ }^{22}$. En esa morada se abre una ventana de conocimiento y contemplación, a janela, metáfora recurrente en la obra de Pessoa. Quien desee ver a través de la apertura ha de hallarse en la más absoluta desnudez de prejuicios, sobre lo invisible y lo visible, porque ahí, en el envés de ese plano, se muestra el vacío a través del cual hasta la propia Casa, el yo ${ }^{83}$, se aparta en retirada por diferentes ventanas. En ese ámbito visionario, a medida «que se desvanece el color rojo, emerge el azul que conduce al poniente, el cual indica un movimiento marítimo» ${ }^{84}$ que arrastra al infinito. En ese transcurso se produce la metamorfosis, que «trasmuta la forma física y mental» ${ }^{85}$. Es en ese mapa donde Infausta, la heterónima de Pessoa creada por Llansol, dividida en dos espacios por un plano, gracias a una atenta contemplación, divisa «un espejo quebrado y llameante». Esa mirada cautivada es deudora también del color, ya que fue posible gracias a una «brisa intermedia entre el verde y el blanco por donde el silencio se deslizaba como una niebla acoplándose a la Casa, al jardín y a la sangre [...] $\gg^{86}$. El ardiente deseo (šawq) nace en el corazón, impulsado por una voz interior, la de la conciencia íntima donde anida el secreto (sirr) que se hunde en visitaciones repentinas de mundos invisibles ${ }^{87}$. Pero, quizás para ver en la forma debida no sea tan necesario, como dice Llansol, descorrer velos, sino asumir «posturas, posiciones reales de aquello que es concebido entre el ser presente y el ser» ${ }^{88}$.

Los textos de Llansol nos introducen, de forma muy peculiar, en la complejidad del peregrinaje iniciático, el walāyah sufi, descrito por Ibn 'Arabī. En este caso, la autora dibuja el progreso de un alma errante a través de los reinos vegetal, animal y humano, bajo la sombra del sentido esotérico de las Revelaciones, realzando la permanencia $\left(b a q \bar{a}^{3}\right)^{89}$ de lo que es absoluto y necesario, oscuro objetivo sin final en la vía del Conocimiento.

79 Cf. Ibid., p. 30.

80 Id., Lisboaleipzig, cit. p. 62.

81 Ibid., p. 74.

82 Ibid., p. 62.

83 Cf. Id., Um Arco Singular, cit., p. 227.

84 Id., Lisboaleipzig, p. 62.

85 Ibid., p.52.

86 Ibid., p.64.

87 Cf. Henry Corbin, «Rûzbehân Baqlî de Shîrâz», conférence du 27 novembre 1958, Préface au Jasmin et Henry Corbin, Cahier de l'Herne, Paris, L'Herne, 1981.

88 M. G. Llansol, Lisboaleipzig, cit., p. 56.

89 Ibn 'Arabī, El libro de la Extinción en la Contemplación, cit., p. 13. 
En este camino sagrado ${ }^{90}$ se reproduce el tema arquetípico que tiene por objeto la búsqueda del Manantial divino de la Vida, el de Mnemosine, al lado del cual crece un blanco ciprés, y de donde mana el Agua de la Inmortalidad, el descubrimiento de las imposibles Islas de los Bienaventurados pindáricas

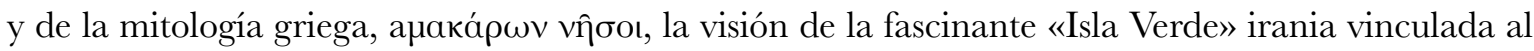
verdor de la tierra de Xvarnah en el zoroastrismo ${ }^{91}$, en definitiva, la indagación de una patria interior y anterior que se transforma en el país sin espacio y «sin tiempo», donde ser feliz consiste simplemente en ser feliz ${ }^{92}$, donde no se siente correr el paso de las horas, ni se desea, ni se sueña, ni se vive[...] ese es el lugar de la infancia $\sin$ fin ${ }^{93}$ en el que en un instante-fulgor desgajado de la eternidad se hace evidente el «pensamiento mirífico del Esse» ${ }^{94}$, dice Maria Gabriela Llansol, el cual de forma paradójica llega a un conocimiento que no se procesa a partir de conceptos y sólo sobreviene a «los caminantes de la noche a los que se muestra este mismo $\operatorname{Esse}^{95}[\ldots]$ a los atletas de una ambición, hechos de un solo vórtice, intensos, exclusiva y metódicamente ocupados en hacer de su vida un lugar» ${ }^{96}$. Dice la escritora portuguesa, el Esse, (noción que a nuestro juicio refleja la presencia del Ser (hadra), «me quiere pensar y me piensa en la noche ${ }^{97}$, lo que denota una incesante actividad de correspondencias noctívagas entre quien piensa y es pensado de otra manera o, mejor, entre quien ama y es amado, según una fórmula neoplatónica en la cual la unidad del amor, el amante y el amado se resuelven en lo Único que se contempla a sí mismo como si de un tesoro oculto se tratara, un tesoro presto a la autorevelación que se da al argonauta, navegante por mares desconocidos, ocupado en la búsqueda de la fuerza íntima originaria que le anima e impulsa al descenso en su propio espacio abisal, nocturno. Este descendimiento resulta un movimiento necesario para alcanzar la unión, ittihâad, fusión que se halla vinculada a una visión casi-física del amor, un amor que si bien nos abandona, regresa a caballo ${ }^{98}$. A este respecto escribe Llansol ${ }^{99}$ : «el Corazón cuanto más revestido está de rebeldía más próximo se halla del amor ardiente», o mejor, «se encuentra ardiendo». Esa es la imagen de lo que la escritora describe como «fiesta de los sentidos contradictorios», irrupción de una fuerza multicolor que al sumergir al sujeto le aleja de la visión ordinaria.

90 G. Colli, La Sabiduría Griega, cit., p. 181.

91 A. G. Carbó, «El viaje espiritual al espacio verde», cit.

92 G. Colli, La Sabiduría Griega, cit., p. 131.

93 F. Pessoa, Poesia do Eu, ed. Richard Zenith, Lisboa, Assírio\& Alvim, 2006, p. 37.

94 M. G. Llansol, Lisboaleipzig, cit., p. 86.

95 Ibid., p.136. Queremos subrayar el juego del infinitivo Esse, en latín «Ser», con el pronombre demostrativo «Esse» en portugués: «Ese», lo que nos remite a un referente prodigioso, a «Ese» algo que está ahí y se hace presencia y que no es otro que el Ser de las cosas.

96 Ibid., p. 101.

97 Ibid., p.135. Traducción nuestra.

98 Id., Um Arco Singular, cit., p. 31.

99 Id., Lisboaleipzig, cit., p. 27. 
En una línea similar a la seguida por los místicos Rūzbehān Baqlī Š̀̄rāzì e Ibn 'Arabī, Llansol sostiene que: «La condición de la unión es la semejanza. Quién se asemeja se une. El semejante es conocido por el semejante» ${ }^{100}$. En esto consiste la fuerza redentora del amor, la espera y preparación para lo que ha de venir, gracias a la cual cesa el conflicto entre el Uno y las diferencias: «Uno en el otro estaba como el amado en su amigo; y este amor que los une tiene el mismo valor en uno que en otro, la misma igualdad» ${ }^{101}$.

Llansol vive en un continente marcado por el amor ${ }^{102}$ y las figuras que recorren sus lugares hechos de verbo, no buscan otra geografia, porque renuncian al poder y al secreto mismo, ya que el secreto es lo desconocido. Sin embargo, es preciso seguir a partir de la escritura las huellas de lo furtivo, de lo velado, del enigma en todo cuanto se siente, de lo que se huele, se toca, se oye, se ve y se saborea, es así como, en lenguaje de Fernando Pessoa, nos posicionamos en el ámbito de una Metafísica de las Sensaciones que conduce a un más allá del yo. Y a partir de este esfuerzo, al-ğihād al-akbar, es como de forma paulatina se produce la extinción del yo, fan $\vec{a}$.

Estas correlaciones eróticas y coloristas de acercamiento, distancia y aniquilación, se dan en el seno de lo velado, opuesto al albor, en las noches-risa llansolianas en las que el alma camina como de noche y en la oscuridad ${ }^{103}$. Pero, quien viaja a través del Hades siempre persigue algo, es atraído por algo o por alguien, claudica ante una apelación, un requerimiento, un reclamo que nace en lo más profundo de sí. Se trata de la búsqueda de la Unidad en la multiplicidad, de la Jerusalén perdida, encuentro que se produce en una especie de comunión, comida maravillosa que guía en el viaje ${ }^{104}$ y que se comparte entre criaturas etéreas reunidas en la Casa, lo que va a dar lugar a la escritura de un libro extraño, el texto que no llegó a ser escrito por San Juan de la Cruz: El libro de las Comunidades, al que le siguen otros en los que ese espíritu corporativo se expande.

En definitiva, estas son reflexiones precisas sobre un cierto tipo de muerte y renacimiento lumínico de carácter espiritual que como muy bien apunta Antoni Gonzalo Carbó, en su artículo El viaje espiritual al espacio verde, nos vincula a la mors mystica en el sufismo ${ }^{105}$ y por extensión al pensamiento imaginal desarrollado por Ibn 'Arabī y también, hay que decirlo, nos acerca a ese tipo de humanos Bienaventurados señalados por María Zambrano, aquellos que al transmutarse en atractores abismáticos traspasan fronteras y alcanzan la blancura del pensamiento:

100 Ibid., pp. 110, 111, 118.

101 Id., El Libro de las Comunidades, cit., p. 40.

102 Cf. Id., Lisboaleipzig, cit., p. 50.

103 Id., El Libro de las Comunidades, cit., p. 12.

104 Ibid., p. 34.

105 A. G. Carbó, «El viaje espiritual al espacio verde», cit. 
Los Bienaventurados nos atraen como un abismo blanco. Esa blancura del pensamiento que sería, [...] esa cima más allá de todo y más allá del Todo [...]. Los bienaventurados se detienen por sí mismos, no han empezado ni siquiera a soñarse ni a ensoñarse a sí mismos, a su propio pensamiento. Están como alojados en el orden divino que abraza sin tocarlas todas las cosas y todos los seres [...] están rondando en silencio en una danza que cuando se hace visible es orden, armonía geométrica. Más de una geometría no inventada, de una geometría dada como un regalo por el Señor de los números y de las danzas, por tanto invisible, insensible, es decir con un mínimo de "materia sensorial'. La danza de lo acabado de nacer o de lo que no ha nacido todavía, o de lo que nunca nacerá, pero la danza que es danza para siempre. ${ }^{106}$

Maria Gabriela Llansol atiende a este requerimiento arcano que interpela a todos los visionarios a través de fotismos coloreados. Atenta a las diversas luminiscencias con las que dispensa la naturaleza en los diversos momentos, al precisar formas a la luz del día resalta el «verdon» ${ }^{107}$ que desde la tierra penetra en el «agua» surcada por un barco «azul». El juego de los matices y tonalidades refleja un sentido espiritual del color, la vivencia interior. Con estas reflexiones se vierte en un lenguaje no apto para quienes transitan por lugares y tiempos ya explorados, comunes, en consecuencia postula una forma de locución que emerge también de una página en «blanco» ${ }^{108}$, ajena al pensar, en la que San Juan de la Cruz escribe en vano, «sin escritura», perdiéndose en ella para volver a nacer, en un paisaje también blanco, invernal, solamente visible por un «corazón» (qalb) saudoso, esperanzado, atento a un verbo conformado por palabras inconexas que «acontecen» balbuceantes, cargadas de significados en un breve fulgor asociado a la belleza serena, al amor y, también, a la reivindicación del espacio de los vencidos, eso es lo que hace su escritura diferente, amable e incómoda, incluso inaccesible, porque los enunciados llansolianos siguen otros derroteros, otras trazas ajenas al discurso habitual.

Muitos dos que me lêem têm dificuldade em ajustar-se ao pacto da leitura que os meus textos supõem: o de saberem quem está enunciando. E sabe-lo sem sombra de dúvida. Os meus textos supõem um pacto de inconforto $[\ldots]$ o meu texto, se dirige, de facto ao ansiar do coração [...] um fulgor estético. ${ }^{109}$

106 M. Zambrano, Los Bienaventurados, Madrid, Siruela, 2004, pp. 69-70. La cursiva es nuestra.

107 M. G. Llansol, El Libro de las Comunidades, cit., p. 22.

108 Cf. Id. $O$ azul imperfeito, cit., p. 262. Llansol hace una referencia a la Claridad y a los grados de la misma: Todo es claro dentro de lo claro, hay círculos concéntricos de claridad, y «el último que alcanzo es infinitamente más claro todavía $[\ldots] »$.

109 Id., Lisboaleipzig, cit., p. 12. 
El color «blanco» representa esa extinción del yo, es la luz que deslumbra y tras la cual mora lo intangible:

Había una claridad tan intensa, que nadie podría soportarla, más que velada; el puente llegaría de arriba, de traspasar el sol [...] A veces en ese nacimiento de la luz se inscribían palabras y frases que se desmoronaban. ${ }^{10}$

La blancura o «la sombra de Dios», en términos de Zambrano, se corresponde tal como nos recuerda Antoni Gonzalo Carbó ${ }^{111}$, a la luz apofática, (ả゙oфávaı), y a la culminación en la progresión de las luces de Ibn 'Arabī, a la «poesía blanca y caótica» ${ }^{112}$ ligada a las visiones, «al esplendor lascivo [...]. Sombra de sombras». «Color blanco de la escarcha propia de un paisaje invernal» ${ }^{113}$ asociado a la muerte / nacimiento de San Juan de la Cruz, quien dijo a Ana de Peñalosa «que iba a morir para describir el momento de la muerte» ${ }^{114}$. Peñalosa participa del viaje de vuelta del místico a través de una topografía también helada alfombrada de «hojas secas recortadas sobre un blanco resplandeciente» ${ }^{15}$ donde quien escribe se fija en «una rama pequeña [...] cubierta de escarcha $[. .$.$] la rama permanece blanca y escarchada porque el frío es glacial», { }^{116}$ un «eco de nieve», en tanto San Juan de la Cruz «escribe en blanco, sobre una hoja en blanco, sin escritura» ${ }^{117}$, prefigurando la blanca «luz de lo invisible» de Ibn 'Arabī, (nūr al-garb $)^{118}$. Esa luz blanca muestra un espacio inmóvil, de quietud y silencio, sólo recorrido por quién se halla en estado de quietud y recurre a la memoria de muerte, cautivada por «una brisa intermedia entre el verde y el blanco por donde el silencio se deslizaba como una niebla acoplándose a la Casa, al jardín y a la sangre $[\ldots]{ }^{119}$.

El blanco refleja un campo de fuerzas imperceptibles que impregna todo el espacio/tiempo en el que ciertas partículas inexistentes, con masa nula, danzan el movimiento de la nada trayendo con su juego de fricciones a la existencia lo que tan sólo pertenecía al universo de los posibles y dormitaba en la Nada esperando ser Todo, en las Tablillas de Orfeo, quien «trajo de Egipto la mayor parte de las iniciaciones místicas y los ritos secretos relativos a sus propias peregrinaciones $[\ldots]{ }^{120}$.

110 Id., El Libro de las Comunidades, cit., p. 39.

111 G. Colli, La Sabiduría Griega, cit., p. 237.

A. G. Carbó, «Exceso de luz blanca que mata: de la "blanca agonía" (Mallarmé) a la "blancura mortal” (Antonio Gamoneda)», Erebea - Revista de Humanidades y Ciencias Sociales, n. ${ }^{\circ}$ 5, 2015, p. 164.

112 M. G. Llansol, Lisboaleipzig, cit., p. 178.

113 Id., El Libro de las Comunidades, cit. p. 30.

114 Ibid., p.36.

115 Ibid., p. 29.

116 Ibid., p.30.

117 Ibid., p.27.

118 A. G. Carbó, «Exceso de luz blanca que mata», cit., p. 156.

119 M. G. Llansol, Lisboaleipzig, cit. p.64.

120 G. Colli, La Sabiduría Griega, cit., p. 237. 


\section{REFERENGIAS BIBLIOGRÁFIGAS}

BACHELARD, Gaston, (1992), Fragmentos de una Poética del Fuego, Barcelona, Paidós.

(1981), L'Air et les songes: essais sur l'imagination du mouvement, Paris, José Corti.

(1972), El aire y los sueños, México, FDCE.

BORGES, Paulo, (2017), «Vazio, Interlúdio e Entresser. A Metamorfose de Fernando Pessoa em Maria Gabriela Llansol», in Aa. Vv., Actas do Congresso Internacional Fernando Pessoa 2017, Lisboa, Casa Fernando Pessoa, pp. 320-330, https://casafernandopessoa.pt/application/files/5315/1698/3454/CFP_ACTAS_2017.pdf.

CARBÓ, Antoni Gonzalo (2015), «Exceso de luz blanca que mata: de la "blanca agonía” (Mallarmé) a la "blancura mortal" (Antonio Gamoneda)», Erebea - Revista de Humanidades y Ciencias Sociales, n. ${ }^{\circ}$, p. 164.

(2003), «El viaje espiritual al espacio verde: El jardín de la visión en el sufismo», ponencia pronunciada en Homenaje a Henry Corbin, Universidad Complutense de Madrid, Casa de Velázquez, Instituto Francés de Madrid, 8 de abril de 2003.

COLLI, Giorgio (2008), La Sabiduría Griega, Madrid, Trotta.

CORBIN, Henry (2015), Acerca de Jung, el Buddhismo y la Sophia, Madrid, Siruela.

(2003), Templo y Contemplación, Madrid, Trotta.

(2000), El Hombre de luz en el Sufismo Iranio. Madrid, Siruela.

(1991), En Islam iranien, vol. III, Paris, Gallimard.

(1981), «Rûzbehân Baqlî de Shîrâz», conférence du 27 novembre 1958, Préface au fasmin et Henry Corbin, Cahier de l'Herne, Paris, L'Herne.

(1958), L'Imagination Créatrice dans le sufisme d'Ibn' Arabî, París, Flammarion.

ELIADE, Mircea (1980), La Prueba del laberinto, Madrid, Cristiandad.

DUFRENNE, Mikel (2010), La Noción de “A Priori”, Salamanca, Sígueme.

(1982), Fenomenología de la Experiencia Estética, Valencia, Fernando Torres.

MORA, Fernando (2015), Ibn al 'Arabî, Vida y enseñanzas del Gran Místico Andalusí, Barcelona, Kairós.

IBN 'ARABĪ (2018), Tratado del Amor, Madrid, EDAF.

(2007), El libro de la Extinción en la Contemplación, Málaga, Sirio.

(2002), El Intérprete de los Deseos, Murcia, Editorial Regional.

KANDINSKY, Vasili (1981), De lo espiritual en el arte, Barcelona, Barral. 
LLANSOL, Maria Gabriela (2015), O Azul Imperfeito, Livro de Horas V, Porto, Assírio \& Alvim. (2014), Geografia de Rebeldes, Madrid, Cinca.

- (2014), Lisboaleipzig, O encontro inesperado do diverso. O ensaio de música, Porto, Assírio \& Alvim. (2010), Um Arco Singular, Livro de Horas II, Lisboa, Assírio \& Alvim. (2005), El Libro de las Comunidades, Madrid, Visiónnet. (1988), Da Sebe ao Ser, Lisboa, Rolim.

MAESTRO ECKHART (1998), «Sermón 52», in id., Beati pauperes spiritu, México, Consejo nacional para la cultura y las artes, Dirección General de Publicaciones.

PARMÉNIDES (1983), Poema, Barcelona, Orbis.

PESSOA, Fernando (2006), Poesia do Eu, ed. Richard Zenith, Lisboa, Assírio \& Alvim.

__ (2004), «Pasos de la Cruz», XI, in id., Ficciones de Interludio, Buenos Aires, Emecé.

ZAMBRANO, María (2004), Los Bienaventurados, Madrid, Siruela. (2001), Filosofía y Poesía, Madrid, Fondo de Cultura Económica. 